\title{
O método científico como ferramenta de aprendizagem nos anos finais do ensino fundamental
}

> $>>>>>>>>>>>>>>>>>>>>>>>>>>>>>>>>>>>>>>>>>>>>>>>>>>>>>>>>>>>>>>>>>>>>>>>$

Cristina Claumann Freygang*

\section{Resumo:}

Este relato retrata a atividade realizada no período de 2012 e 2013, com alunos das séries finais da EMEF João Paulo I, em Canoas/RS. O trabalho foi desenvolvido durante as aulas e, também, com um grupo de cerca de vinte alunos voluntários, em reuniões quinzenais, de 45 minutos, em turno inverso. Visando a despertar o interesse e a criatividade, a relacionar a prática com a teoria e a introduzir o método científico, o projeto desenvolveu-se em várias etapas, aumentando-se progressivamente o nível de autonomia dado aos alunos. Durante esse período, pôde-se notar uma mudança no comportamento dos alunos, não apenas em relação à curiosidade, mas, também, à forma como passaram a se relacionar com experimentação, tornando-se mais organizados e questionadores. Observaram-se mudanças, também, na postura em sala de aula. A desvantagem de trabalhar desta forma é que o grupo de alunos atendidos de maneira mais individualizada no turno inverso é pequeno.

\section{Palavras-chave:}

Método científico. Experimentação. Ciências. Anos finais.

\begin{abstract}
:
The activity took place from 2012 to 2013 with upper elementary school students at EMEF Joao Paulo I in Canoas/RS. The work was developed during classes and with a group of approximately 20 volunteer students from different grade levels in a series of 45 minute encounters that took place at 15 days intervals outside of the volunteer students' normal class time. To achieve the objectives, the project was developed in several stages where the level of autonomy given to the students increased progressively over time. During this period, there was a noticeable change in the students; they became more active, organized and inquiry-based in their learning. These attitudes were also reflected in the way the students interacted, becoming more positive in the classroom. The disadvantage of using this model of instruction is that the group who attended the encounters outside of their normal class time is small.
\end{abstract}

\section{Keywords:}

Scientific method. Experimentation. Science. Upper elementary school.

* > Professora de Ciências das séries finais do Ensino Fundamental e bióloga. Doutora em Ciências (Genética e Biologia Molecular). Prefeitura de Canoas. E-mail: crisfreygang@yahoo.com.br. 


\section{Introdução}

Nos últimos anos, o desenvolvimento da ciência e da tecnologia tem provocado mudanças drásticas na sociedade e, com isso, cresce a preocupação com a capacidade do cidadão em se adaptar às novas realidades, pois o aluno não deve apenas aprender, ele deve ser estimulado a estabelecer relações com o ambiente, ter posicionamento em relação à sociedade, compreender a influência e a importância que a ciência e a tecnologia têm em sua vida e, então, por consequência, ter atitudes que reflitam a assimilação/aprendizado do conteúdo ministrado (VERONEZ et al. 2009, p. 34). Segundo Teixeira et al. (2013), quando o homem adquire um bom embasamento científico, ele está mais preparado para o diálogo e a tomada de decisão.

Nosso atual modelo de organização social vem legando aos sistemas educacionais a tarefa de contemplar uma formação ampla e diversificada. A escola deve preparar os indivíduos para a vida, para seu bem-estar e para atuar de forma crítica e consciente nos eventos presentes no mundo circundante (ROSA et al., 2007, p. 264). Assim, não é mais possível conceber que o sistema educacional tenha por fim apenas questões propedêuticas ou unicamente direcionadas para o mundo do trabalho. É necessário que ele apresente, em sua estrutura organizacional, elementos que permitam aos jovens uma formação para a vida. Os currículos necessitam contemplar questões que ultrapassem os conhecimentos específicos das disciplinas escolares, buscando envolver elementos como valores, atitudes, emoções, hábitos etc. (ROSA et al., 2007, p. 264).

Nesse sentido, o ensino de ciência deve ser entendido como "[...] uma alavanca preciosa para o desenvolvimento da passagem à abstração, das capacidades de raciocínio e de antecipação, favorecendo o acesso a novas operações mentais" que, para as crianças, representa a iniciação à formação do espírito científico (ASTOLFI et al., 1998, p. 103). O espírito científico pressupõe iniciação à dedução, ao raciocínio lógico e também representa a inventividade das hipóteses e a formulação de problemas, não podendo visar apenas aos conhecimentos dos conceitos e fenômenos específicos da disciplina (ASTOLFI et al., 1998). Para esse autor, atividades experimentais são a oportunidade de avançar sobre o plano da combinatória lógica da matemática e aproximar os estudantes de situações reais, oportunizando as operações lógicas, e o desenvolvimento de habilidades manuais e técnicas, ao mesmo tempo em que encoraja os estudantes à probidade intelectual e moral (ASTOLFI et al., 1998).

Além desses apontamentos, referentes à importância das atividades experimentais no ensino de ciências, há outras questões que vêm se fazendo presentes nesse contexto, conforme destaca Hodson (1988) ao mencionar que há outras funções pedagógicas nesse componente curricular, além do cognitivo. Para ele, as atividades experimentais também têm por objetivo estimular a confiança e a autoestima dos alunos, mostrar às crianças que elas podem manipular e controlar eventos, ou mostrar que elas podem investigar e solucionar problemas - ou, pelo menos, tentar, pois já diz o senso comum que aprender é se arriscar a errar e só não erra quem não tenta.

Esse processo de curiosidade busca a transmissão de um conhecimento e faz com que o aluno passe de um ser passivo no seu aprendizado para ativo, não só no aspecto cognitivo, mas nas relações sociais dentro e fora da sala de aula. Quebra-se, então, o paradigma educacional em que o professor é o único detentor do conhecimento para se dar lugar a um aluno agente, capaz de investigar cientificamente e de buscar respostas aos seus questionamentos. Além disso, ao entender o aluno como parte integrante do processo de construção do saber, todas as experiências já vivenciadas por ele passam a permear o conhecimento, aproximando este da realidade dos alunos (SILVA et al., 2008, p. 64). 
Não é à toa que uma propaganda de televisão afirma “[...] não são as respostas que movem o mundo e sim as perguntas”. Quem convive com jovens não tem dúvida: perguntar é uma necessidade. Do ponto de vista pedagógico, eles estão corretos: perguntar é uma das maneiras mais eficientes de conhecer o mundo (MOÇO, 2009). Para Hodson (1994, p. 306) os pequenos devem ser estimulados a explorar suas opiniões colocando a prova suas capacidades para a explicação e, quando notam que suas ideias não são adequadas, pode-se incentivá-los a produzir novas questões.

Segundo Moço (2009), em Ciências:

A estrutura que permeia as investigações tem, ao menos, quatro passos fundamentais. O primeiro deles, o levantamento de hipóteses, é uma decorrência do questionamento inicial. É o passo em que os pequenos expõem ideias que serão comprovadas ou refutadas mais adiante. Ao imaginar caminhos para tentar resolver um problema, o aluno reconstrói o conhecimento. E isso é justamente um dos principais objetivos da educação escolar.

A etapa seguinte é o levantamento de informações. Além de ampliar o conhecimento sobre o tema pesquisado, ajuda a criança a treinar o olhar para a observação científica, sabendo melhor o que anotar em uma experiência prática, por exemplo. Levando revistas, livros e textos científicos para a sala, você pode deixar a turma explorar o material e ler os textos mais significativos. Se aparecerem conceitos difíceis, é preciso explicá-los sem reduzir o sentido; por isso é tão importante se preparar e conhecer profundamente o objeto de pesquisa.

O terceiro momento pode ser o da experimentação, geralmente tido como o ápice do projeto, mas que deve ser encarado apenas como mais uma etapa da aquisição de conhecimento. Por último, vem a fase da síntese, e a recomendação é que a experiência seja documentada em textos ou desenhos. Conteúdo procedimental obrigatório, o registro permeia todas as etapas e contribui para que o aluno reflita sobre suas hipóteses iniciais, dando mais um passo para comprová-las ou não.

Entretanto, muitas vezes, a experiência pode deixar velhas dúvidas no ar ou suscitar novas - cabe então ao educador avaliar se elas justificam outro projeto de estudo ou se podem ser sanadas com o aprofundamento da pesquisa. Se for esse o caso, vale incentivar a turma a seguir vasculhando a resposta. Não importa o método: o que interessa é mostrar a importância de pesquisar e aprender com uma variedade de fontes (MOÇO, 2009).

A existência de um ambiente de discussão, estudo e debate da ciência, afastado da rigidez da sala de aula é de fundamental importância, pois o domínio da cultura científica é instrumento indispensável à participação política e cidadã. Não há como participar de uma sociedade como agente de transformação sem um conhecimento científico básico. Trata-se de uma condição essencial para formar pessoas criativas e participativas, capazes de atuar na sociedade (SILVA et al., 2009).

\section{Justificativa}

Observando-se as turmas de nossa escola, percebe-se que estas apresentam dificuldades para aprenderem os conceitos científicos previstos no ensino de ciências, devido, entre outras causas, a dificuldades de raciocínio lógico e interpretação, além de uma falta de comprometimento em relação às questões escolares, fato notado em todas as turmas dos sextos anos até as oitavas series (atual 9o ano).

Para realizar este projeto, pensou-se que atividades investigativas e em sala de aula, que incentivassem o educando a se envolver progressivamente com as manifestações dos fenômenos estudados, levantando hipóteses, experimentando, errando, interagindo com 
colegas e professores, expondo seus pontos de vista, suas suposições, debatendo-os com os outros e com os resultados experimentais para testar sua validade - o que facilita a aprendizagem de conceitos científicos e de entendimento do seu próprio cotidiano, acabando por desenvolver no aluno novas atitudes com relação ao mundo em que vive, além de proporcionar um espaço fora do horário de aula, para a prática e discussão científica.

\section{Objetivos}

Atividades como essa têm a finalidade de criar um ambiente propício para o desenvolvimento de diversas habilidades, tendo como base a ciência, a tecnologia, a sociedade e o meio ambiente, já que as questões científicas não estão isoladas do contexto social, político, ambiental e econômico dos estudantes. Sendo assim, esse trabalho teve por objetivos:

- Despertar o interesse, a criatividade e o gosto pela ciência nos educandos;

- Estabelecer uma relação entre ciências e cotidiano, para que o aluno possa entender o porquê de várias situações ao seu redor, levando-o a relacionar a prática com a teoria, além de trabalhar alguns conceitos específicos da disciplina de Ciências;

- Introduzir o método científico buscando fazê-los compreender que este é uma ferramenta para resolver não apenas as questões sobre o mundo e o universo em que vivemos, mas os problemas comuns do cotidiano, usando uma abordagem objetiva e padronizada na condução de experiências, para que as observações geradas destes possam ser passíveis de repetição, além de trabalhar aspectos do método científico, como a observação, generalização, entre outros;

- Entender que a ciência não deve realizar julgamentos de valores, que os problemas devem ser analisados sob mais de uma perspectiva antes de se chegar a conclusões e que os conhecimentos produzidos pela ciência não são imutáveis, mas que podem se aperfeiçoar de acordo com as novas descobertas que vão sendo realizadas;

- Ajudar o aluno a melhorar a sua argumentação, o que possibilita desenvolver o espírito de análise na escolha entre as diferentes alternativas e trabalhar a questão do comprometimento, pois, segundo Lameira (2009, p. 154), a investigação obriga a uma maior atenção aos fatos e fenômenos que normalmente não perceberíamos e nos obriga a ter uma disciplina tanto na observação em si quanto nos registros que devam ser feitos.

\section{Desenvolvimento}

A atividade foi realizada no período de 2012 e 2013, com os alunos da Escola Municipal de Ensino Fundamental João Paulo I, no município de Canoas - RS. Essa atividade foi realizada em duas frentes: uma durante as aulas regulares de Ciências, com todas as turmas; e outra com um grupo inicial de cerca de quinze alunos voluntários e alguns outros alunos convidados, por se mostrarem curiosos e participativos, os quais, no entanto, apresentavam problemas de comprometimento e conduta em sala de aula. Os alunos desse grupo vinham à escola quinzenalmente para reuniões de 45 minutos, no turno inverso, totalizando cerca de vinte alunos. Este número variou ao longo da atividade.

Em sala de aula, além de outras pequenas práticas, estabeleceu-se, para cada série/ ano, experiências-chave para trabalhar o método científico que deveriam culminar com a redação de um relatório de aula prática. Nos $6^{\text {os }}$ anos, escolheu-se um experimento para a demonstração do ciclo da água. Nos $7^{\text {os }}$ anos, trabalhou-se com duas experiências: a primeira foi uma aula de microscopia sobre protozoários e outros micro-organismos, no segundo trimestre, e a segunda foi uma observação no terceiro trimestre sobre fungos, 
realizada solicitando aos alunos que observassem pedaços de pão em suas casas durante quinze dias e anotassem os resultados. Na sétima série (atual $8^{\circ}$ ano), trabalhou-se com uma prática de frequência cardíaca e, na $8^{\text {a }}$ série (atual $9^{\circ}$ ano), com um trabalho sobre densidade no primeiro trimestre e um trabalho de cálculo de velocidade no último.

Independentemente da prática, inicialmente, trabalhava-se o conteúdo formal com os alunos, por meio de leituras, explicação oral e pequenos vídeos, para fornecer um embasamento teórico inicial para a realização das próximas etapas.

Após os alunos já possuírem informações suficientes, algumas atividades desdobravamse em outras. Um exemplo foi o estudo sobre fungos, em que se organizou uma mesa-redonda na qual se discutiu a importância dos fungos (suas aplicações no nosso dia a dia, suas funções para o meio ambiente) e como seria a nossa vida sem eles. A seguir, os alunos reuniram-se em pequenos grupos e foi solicitado que escrevessem um texto cujo tema era "e se os fungos entrassem em greve?", no qual deveriam imaginar uma greve geral dos fungos e como seriam o mundo e suas próprias vidas se isso acontecesse. Os textos poderiam ser escritos no gênero textual que preferissem, utilizando inclusive outras linguagens (histórias em quadrinhos, por exemplo), se assim quisessem, incentivando, desse modo, a oralidade, a criatividade, e tentando estabelecer relações entre teoria e prática.

Após, trabalhou-se o método científico em si. Para isso, os alunos foram levados ao laboratório de ciências, onde criou-se uma hipótese baseada em uma observação fictícia, que, no caso, era a de que iogurte de ameixa poderia curar o câncer. Com base nessa hipótese inicial, incentivou-se os alunos a elaborarem formas de testar se essa hipótese era verdadeira. Então, houve uma explicação de como o experimento poderia ser desenvolvido na vida real, já aproveitando para introduzir o conceito da importância de ter a metodologia bem descrita, para que possa ser testada por outras pessoas, o conhecimento das técnicas necessárias, o que são os controles positivo e negativo (sem, contudo, utilizar esta nomenclatura ainda) e como podem ajudar. Aproveitamos este momento para mostrar alguns materiais de laboratório que poderiam ser usados neste experimento. A partir das metodologias estabelecidas, criaram-se alguns resultados possíveis e questionou-se a que conclusões aqueles resultados poderiam levá-los.

Depois desta primeira explanação, os experimentos eram propostos aos educandos. A seguir, explicou-se como elaborariam o relatório de aula prática que iriam entregar (eles tiveram, aproximadamente, um mês para confeccionar o relatório, que deveria conter introdução, metodologia, resultados, conclusão e, inclusive, referências bibliográficas, pois considerou-se que eles já têm maturidade para entender que, se algumas informações que utilizaram para confeccionar os relatórios vieram de outras fontes, elas devem ser citadas, não sendo cobrado, contudo, normas técnicas). Nesta fase, também, assistiu-se a um vídeo do programa de televisão Mundo de Beakmann sobre o método científico.

Para exemplificar o trabalho desenvolvido com o turno inverso, escolheu-se, aqui, relatar o realizado com a parte deste grupo pertencente aos 6os / 7os anos. Para atingir os objetivos do trabalho, o projeto desenvolveu-se em várias etapas ao longo de quase dois anos.

Durante o começo do ano de 2012, montou-se uma miniestação de previsão do tempo com termômetro, barômetro e um pluviômetro, este último, instalado em um dos pátios da escola. Ensinamos os alunos a utilizá-los e anotou-se diariamente os dados coletados com os equipamentos, com exceção dos finais de semana e dias de planejamento da professora, nos quais estes dados foram obtidos pelo site do Climatempo. Por questões práticas, como o grupo não possuía ainda nenhuma vivência em projetos de pesquisa e apresentava uma certa desorganização, essas anotações ficaram a cargo da professora.

Após a definição do projeto com os alunos, o grupo passou a reunir-se para trabalhar com assuntos como: montagem de gráficos, tabelas, funcionamento de cada aparelho, construção de aparelhos (como pluviômetros caseiros, para comparar com os dados do 
instrumento oficial do laboratório). O projeto culminou com um trabalho para a Feira Multidisciplinar da Escola.

Após a feira Multidisciplinar, no terceiro trimestre de 2012, elaborou-se o projeto de uma geladeira sem eletricidade, para a semana da Consciência Negra, por tratar-se de um projeto científico desenvolvido por um cientista nigeriano, que criou esse produto para ajudar as famílias mais carentes a preservar seus alimentos em seu país, já que elas não possuíam eletricidade. Neste trabalho, começou-se a dar mais autonomia para os alunos. Para esse projeto, mostrou-se o vídeo de como montar a geladeira e deixou-se que os alunos organizassem o experimento e a explicação sozinhos, cabendo ao professor um papel de orientação, tirando as dúvidas e ajudando na organização das ideias dos alunos.

No ano de 2013, as reuniões quinzenais começaram no final de abril e, dessa vez, deixou-se a proposta de projeto inteiramente a cargo dos alunos, que resolveram escolher um projeto de extração de DNA do morango. A partir desse projeto inicial, conversou-se com os alunos sobre a diferença entre um trabalho de feira de ciências e um projeto de iniciação científica. Como resultado desta etapa, os alunos resolveram testar o experimento sozinhos em casa para chegar à reunião, que se marcou por esta finalidade, já com o resultado pronto.

Como a experiência funcionou, passaram a testar a mesma técnica para extrair DNA de outros alimentos, como o ovo, por exemplo. Também acharam que o DNA era muito claro e ruim de mostrar, então, decidiram tentar corá-lo. Na reunião seguinte, trouxeram seus resultados, mas seus novos experimentos não se encontravam sistematizados. Dessa forma, não se podia concluir quase nada a partir deles. Então, conversou-se sobre a necessidade de isolar variáveis para definir qual está gerando os resultados.

Finalmente, os alunos optaram por testar a técnica no laboratório de ciências mais uma vez, para confirmar se o que encontraram era realmente DNA, e, dessa vez, optaram por extrair o da cebola. Terminada a extração, concluíram que o DNA extraído era muito pouco em relação ao encontrado na extração do morango e acabaram por elaborar a hipótese de que a quantidade de DNA poderia estar relacionada à quantidade de suco encontrada no material.

Depois de algum debate, decidiram, então, testar a hipótese em casa com uma laranja. Toda essa etapa foi desenvolvida sem interferência do professor.

No dia seguinte, informaram que a experiência havia funcionado, concluíram que a hipótese era correta e, a partir disso, passaram a elaborar a apresentação do trabalho na feira Multidisciplinar de 2013. Este experimento, juntamente com outros três trabalhos também desenvolvidos neste projeto (geladeira sem eletricidade, teste de um meio de cultura caseiro e fluorescência), foi escolhido para ser apresentado na Feira Municipal de Ciências (FEMUCI).

\section{Considerações finais}

Ao iniciar-se o planejamento das atividades em sala de aula, muitas dúvidas surgiram sobre que estratégias utilizar para fazer com que a maioria dos alunos concluísse, por exemplo, os experimentos em casa e sem a supervisão de seu professor. Mas, aparentemente, baseando-se nos relatórios e depoimentos recebidos dos alunos durante essa etapa, nota-se que muitos alunos ficaram encantados com o que observaram, o que os incentivou a ir até o final.

Em uma das sondagens realizadas no início de 2013 nas turmas, solicitou-se, entre outras atividades, que os alunos falassem o que lembravam sobre os conteúdos do ano anterior (no caso, 2012, ano em que se iniciou o trabalho). O questionamento demonstrou que as experimentações fizeram com que a maioria dos alunos lembrasse algo sobre esses conteúdos específicos, até mais que outros conteúdos, que também chamaram suas 
atenções naquele ano, como a montagem de sua própria chave de classificação dos seres vivos da escola. Quando solicitados para falarem sobre a atividade de que mais gostaram no ano anterior, esses experimentos foram citadas por muitos alunos, demonstrando que alguns dos objetivos do projeto foram alcançados.

Algumas atividades, como a mesa-redonda sobre a greve dos fungos, poderiam ter funcionado melhor se os alunos estivessem mais acostumados a expor suas opiniões oralmente, mas houve manifestações suficientes para esta fase do trabalho funcionar. $\mathrm{O}$ texto escrito após a mesa-redonda demonstrou que os alunos, muitas vezes, têm dificuldade de colocar no papel o que expõem verbalmente, mas alguns grupos apresentaram narrações ou textos que lembravam manchetes jornalísticas sobre o tema, além de várias histórias em quadrinhos, o que tornou essa fase muito interessante.

Observou-se que a grande maioria dos alunos conseguiu fazer o trabalho de observação e elaborar um relatório simples. Muitas vezes, houve dificuldade de separar resultados de conclusões ou em organizar o relatório conforme o solicitado. Alguns alunos não conseguiram, também, relacionar os seus resultados com suas conclusões, baseando estas no que pesquisaram para a introdução e nas discussões em aula, e não no que observaram. Contudo, quando solicitados em 2013 que realizassem um relatório de aula prática para as aulas, foram capazes de realizar de maneira mais satisfatória o trabalho.

No que se refere ao trabalho em turno inverso, é inegável a contribuição desse tipo de atividade para o processo de formação dos estudantes em suas diferentes dimensões, sendo importante para a inserção do jovem no Ensino Superior, no mercado de trabalho e, principalmente, para o desenvolvimento de uma atitude curiosa e engajada em relação à transformação da sua própria vida e do seu mundo.

Nesse sentido, o trabalho que é desenvolvido na iniciação científica deve possibilitar que o próprio estudante elabore a coerência interna de suas explicações acerca do objeto de estudo, estabelecendo relações com a realidade mediadas pelo adulto. Assim, o conhecimento é considerado como algo construído na interação desse estudante com o mundo, preservando, alterando ou difundindo essas aquisições por meio das trocas sociais, conforme Farias et al. (2012, p. 260-261).

Durante os quase dois anos de trabalho com este grupo, pôde-se notar uma mudança dos alunos, não apenas com relação à curiosidade e à forma como passaram a se relacionar com as experiências trabalhadas neste período, tornando-se mais ativos, organizados e questionadores, mas também na postura em sala de aula, com alguns deles passando de alunos-problema para alunos mais atentos e comprometidos com entrega de trabalhos e estudos. Isso pode ser constatado em outros estudos, como o de Farias et al. (2012), que afirma que outra questão relevante, a qual transcende o próprio trabalho em si, é a possibilidade de estabelecer um vínculo aprofundado com esses estudantes. Por meio de uma troca efetiva que alterna fala e escuta de conceitos prévios, de necessidades, de dúvidas, de hipóteses e de problemas do cotidiano escolar, pode-se constituir uma "escala de valores" por meio da qual importantes aprendizagens ocorrem para todos que participam desse processo.

A atividade desenvolvida revelou que os alunos, ao sentirem-se envolvidos com o objeto do conhecimento, sentem-se mais atraídos por ele, sendo despertados o interesse e a motivação para a aprendizagem. A mesma atividade foi desenvolvida também com alunos das $8^{\text {as }}$ séries em 2012, mas sem o mesmo resultado, pois, ao chegar próximo do final do ano, esses encontravam-se mais preocupados com os detalhes da formatura, deixando de participar ativamente do processo. Já em 2013, dois dos projetos realizados em turno inverso foram realizados por alunos das $8^{\text {as }}$ séries ( $8^{\text {os }}$ anos em 2012 ), o que também pode demonstrar que este tipo de trabalho surte efeito em longo prazo.

A desvantagem de trabalhar dessa forma (no turno inverso) é que os grupos de alunos atendidos são pequenos e uma grande parcela dos alunos não tem a oportunidade de participar. A dificuldade de trabalhar a experimentação com muitos alunos é uma 
queixa recorrente dos docentes que afirmam que o grande número de alunos por turma se torna o maior empecilho para a realização de atividades experimentais, ocasionando o predomínio de aulas expositivas, segundo Salgado (2013).

Para minimizar este problema, talvez, uma próxima fase seja, quando o grupo participante estiver mais maduro, já que ainda têm dificuldade na capacidade de síntese e organização do que observam, transformá-los em alunos monitores de novos grupos ou, então, propor a criação de um clube de ciências na escola. Outra proposta seria, no futuro, realizar um projeto de alfabetização científica, envolvendo as professoras das séries iniciais, visando não somente a trabalhar questões como a busca de informações, formulação de hipóteses, análise e de síntese, mas também a imaginação e o encantamento inerentes às atividades investigativas desde o início da vida escolar.

\section{Referências}

ASTOLFI, Jean-Pierre; PETERFALVI, Brigitte; VÉRIN, Anne. Como as crianças aprendem as ciências. Tradução: Maria José Figueiredo. Lisboa: Instituto Piaget, 1998. 310p.

FARIAS, Stela Maris Vaucher; SILVA, Lucas Eduardo Ebbsen; SCHWARTZHAUPT, Richele Moreira; BECKER, Maria Luiza Rheingantz. Desenvolvimento de pesquisa científica no CAp/ UFRGS. Cadernos de Aplicação, Porto Alegre, v. 25, n. 1, jan./jun., p. 257- 268, 2012.

HODSON, Derek. Experiments in science and science teaching, Educational Philosophy \& Theory, 20, pp. 53-66. 1988. Disponível em: http://www.iq.usp.br/palporto/TextoHodsonExperimentacao. pdf. Acesso em 10 maio 2013.

. Hacia um Enfoque más Crítico del Trabajo de Laboratório. Enseñanza de lãs Ciências, v. 12, n. 3, p. 299-313, 1994

LAMEIRA, Leocadio. A relevância das disciplinas indagativas na formação de professores para as séries iniciais do ensino fundamental. Educação e Cidadania n. 11, p. 139-159, 2009.

MOÇO, Anderson. Iniciação científica nas séries iniciais. Nova Escola online, ed. 220. 2009. Disponível em: http://revistaescola.abril.com.br/ciencias/fundamentos/quero-ver-mundo-427356.shtml. Acesso em: 10 maio 2013.

ROSA, Cleci Werner da; ROSA, Álvaro Becker da; PECATTI, Claudete. Atividades experimentais nas séries iniciais: relato de uma investigação. Revista Electrónica de Enseñanza de las Ciências, v. 6, n. 2, p. 263-274, 2007.

SALGADO, Elves Santos. Experimentação no ensino de ciências em escolas de ensino fundamental. Planaltina. 2013. 18fs. Trabalho de Conclusão de Curso (Licenciatura em Ciências Naturais). Universidade de Brasília, Brasília, 2013.

SILVA, Jeremias Borges da; COLMAN, Jordana; BRINATTI, André Mauricio; SILVA, Silvio Luiz Rutz da; PASSONI, Sabrina. Projeto criação clubes de ciências. Revista Conexão UEPG, v. 4, n. 1, p. 63-66, 2008.

TEIXEIRA, Hebert José Balieiro; ALMEIDA, Danielle Portela de; SILVA, Thaiany Guedes da; FACHÍN TERÁN, Augusto. A educação científica e os processos cognitivos: reflexões sobre sua evolução até nossos dias. In: 3 Simpósio em educação em ciências na Amazônia - III SECAM. VIII Seminário de Ensino de Ciências. II Fórum de educação, divulgação e difusão em ciências no Amazonas. Manaus - AM, 24 a 27 de setembro de 2013.

VERONEZ, Wanderley Marcílio; SCHIBICHESKI, Bruna Corina Emanuely; SUTIL, Elisama; BRINATTI, André Maurício; SILVA, Jeremias Borges da; SILVA, Silvio Luiz Rutz da; COLMAN, Jordana. A utilização do terrário para conscientização ambiental de estudantes do ensino básico. Revista Brasileira de Ensino de Ciência e Tecnologia, v. 2, n. 3, set./dez, p. 31-40, 2009. 